\title{
AVALIAÇÃO DA DIVERSIDADE FENOTÍPICA EM RAMBUTEIRAS (Nephelium lappaceum) COM BASE NA QUALIDADE DOS FRUTOS ${ }^{1}$
}

\author{
CÉLIO KERSUL DO SACRAMENTO ${ }^{2}$, JAMES NASCIMENTO GATTWARD ${ }^{3}$, \\ WALDEMAR DE SOUSA BARRETTO ${ }^{4}$, SÉRGIO JOSÉ OLIVEIRA RIBEIRO ${ }^{5}$, DARIO AHNERT 6
}

RESUMO - O rambotã (Nephelium lappaceum L.), fruta originária da Ásia, é cultivado comercialmente no Brasil, nos Estados da Pará e Bahia, mas devido à propagação sexuada, apresenta grande variabilidade para características morfológicas e químicas dos frutos. Visando a identificar potenciais matrizes, foram avaliados, em Ituberá-BA, frutos de 105 genótipos de rambotã com base na coloração da casca, suculência e teor de sólidos solúveis. Nesse grupo de plantas, 80 genótipos $(76,2 \%)$ apresentaram frutos com teor de sólidos solúveis igual ou superior a $16^{\circ}$ Brix e tiveram uma amostra coletada para análise em laboratório. Após a pesagem, foram identificados 20 genótipos cujos frutos apresentaram peso médio acima de $30 \mathrm{~g}$ e foram submetidos às análises físico-químicas. Os genótipos avaliados apresentaram frutos com peso médio de 33,2 g (30,2 a 39,4 g), rendimento do arilo de 42,3\% (35,1 a 50,2\%), sólidos solúveis de 17,6 ${ }^{\circ}$ Brix ( 15,8 a $19,7^{\circ}$ Brix $)$ e acidez titulável $0,44 \%(0,19$ a $0,86 \%)$. A amostra de rambuteiras avaliadas apresentou grande variabilidade fenotípica e permitiu a identificação de 2019 ou 19,05\% do total de genótipos avaliados, cujas características dos frutos atendem aos padrões estabelecidos em outros países (peso acima de $30 \mathrm{~g}$ e sólidos solúveis acima de $16^{\circ}$ Brix).

Termos para indexação: seleção, características físico-químicas, variabilidade genética, rambotã.

\section{EVALUATION OF PHENOTIPIC DIVERSITY IN RAMBUTAN TREES (Nephelium lappaceum) BASED ON FRUIT QUALITY}

\begin{abstract}
The rambutan (Nephelium lappaceum L.) fruit originated from Ásia is commercially growth in the states of Pará and Bahia, Brazil, but due to sexual propagation, it shows great variability to morphological and chemical characteristics of the fruits. In order to select potential matrices, fruits of 105 genotypes of rambutan grown in Ituberá, BA were evaluated, based on fruit size, coloration of epicarp and soluble solids. In this sample, 80 genotypes $(76.2 \%)$ presented fruits with soluble solids rate $16{ }^{\circ}$ Brix or above and their fruits were analyzed in laboratory. After the weighing were indentified 20 genotypes which presented fruits with average weight above $30 \mathrm{~g}$ and were submitted to physical and chemical analyses. The fruits from these genotypes showed medium weight of $33.2 \mathrm{~g} \mathrm{(30.2} \mathrm{to} 39.4 \mathrm{~g}$ ); aril percentage of $42.3 \%$ ( 35.1 to $50.2 \%$ ), soluble solids $17.6^{\circ}\left(15.8\right.$ to $\left.19.7^{\circ} \mathrm{Brix}\right)$ and acidity $0.44 \%(0.19$ to $0.86 \%)$. The evaluated plants showed high phonotypical variability and it was possible to identify 20 genotypes or $19,05 \%$ of total of genotypes evaluated which presented characteristics of fruit weight and soluble solids which attended to patterns recommended in other producer countries (fruit weight above $30 \mathrm{~g}$ and soluble solids above $16^{\circ} \mathrm{Brix}$ ). Index terms: selection, physical-chemical characteristics, rambutan.
\end{abstract}

\footnotetext{
'(Trabalho 167-12). Recebido em: 20-05-2012. Aceito para publicação: 28-08-2012. Pesquisa financiada pela Fundação de Amparo à Pesquisa do Estado da Bahia, FAPESB

Engenheiro Agrônomo, DSc. Prof. Pleno da Universidade Estadual de Santa Cruz, (UESC), Ilhéus, BA.Rodovia Ilhéus Itabuna, km 16, CEP 45.662.000. E-mail:celiokersul@gmail.com

2Engenheiro Agrônomo, MSc. E-mail: james gattward@yahoo.com.br

${ }^{3}$ Tecnico de Laboratório, Centro de Pesquisas do Cacau (CEPLAC). E-mail: waldemarwasb@cepec.gov.br

4Engenheiro Agrônomo, Prof. Titular, DCET/UESC. E-mail: solive2000@gmail.com

${ }^{5}$ Engenheira Agrônoma, Prof ${ }^{\mathrm{a}}$ Adjunta, DCAA/UESC .E-mail: marlene.magalhaes@yahoo.com.br

${ }^{6}$ Engenheiro Agrônomo, Phd, Prof. Pleno UESC/DCET. E-mail: darioa@uesc.br
} 


\section{INTRODUÇÃO}

A rambuteira (Nephelium lappaceum L.), família Sapindaceae, é originária da Malásia, constituindo-se numa das mais importantes frutíferas tropicais cultivadas na Ásia. Os rambotãs são produzidos em panículas e classificados como drupa. Os frutos apresentam formato globoso a ovoide, com tamanho variando de 3,0 a $8,0 \mathrm{~cm}$ de comprimento e de 2,5 a 5,0 cm de largura. A casca ou pericarpo apresenta coloração variando de vermelho-escuro ao amarelo coberta com espículas coloridas de tamanho variável. O peso do fruto varia de 20 a $60 \mathrm{~g}$, sendo 30 a $58 \%$ de arilo, 40 a $60 \%$ de pericarpo (casca) e 4 a $9 \%$ de semente. O arilo é translúcido, branco a amarelo-claro, com espessura entre 8 e $15 \mathrm{~mm}$, cujo sabor pode variar de muito doce a distintamente ácido, sendo também variáveis o conteúdo e a textura. O rambotã é consumido principalmente fresco, mas pode ser também utilizado em forma de doce desidratado, compota e geleia (SACRAMENTO et al., 2009).

No Brasil, o rambotã é cultivado em pequenas áreas na Bahia e Pará, com excelente desempenho em produção e qualidade de frutos, despontando como uma alternativa viável devido a sua aceitação no mercado nacional e internacional. Os plantios de ambos os Estados foram formados por meio de sementes, proporcionando grande variabilidade genética. Essa variabilidade pode manifestar-se fenotipicamente através dos frutos em relação à coloração da casca, tamanho e peso dos frutos, rendimento de arilo, acidez, $\mathrm{pH}$, teor de sólidos solúveis da polpa e aderência do arilo à semente (SACRAMENTO et al., 2009).

Conforme Pohlan et al. (2008), não há um padrão internacional para o mercado de rambotãs in natura, entretanto relata que tem sido consenso que os frutos tenham peso de, no mínimo, $30 \mathrm{~g}$, rendimento de arilo acima de $45 \%$ e teor de sólidos solúveis mínimo de $18^{\circ}$ brix, entretanto Kader (2012) sugere o teor de sólidos solúveis acima de $16^{\circ}$ Brix e frutos com peso médio a partir de $30 \mathrm{~g}$, enquanto Medlicott (2012) sugere frutos com peso acima de $30 \mathrm{~g}$ e teor de sólidos solúveis em torno de $18^{\circ}$ Brix.

Sacramento et al. (2007) avaliaram genótipos de rambuteira cultivados no município de Ituberá-BA, e verificaram variações de 21,7 a $41,8 \mathrm{~g}$ para peso do fruto, 30,2 a 48,9\% de rendimento de arilo e 10,8 a 19,7 ${ }^{\circ}$ Brix para sólidos solúveis. Em Jaboticabal-SP, Andrade et al. (2008) relataram variação de 19,5 a 40,4 g para peso médio de rambotãs, 18,0 a $50,8 \%$ para rendimento de arilo e 7,93 a 19,50 ${ }^{\circ}$ Brix para sólidos solúveis. Arenas et al. (2010) avaliaram cinco seleções de rambuteira cultivadas no México e verificaram peso médio de frutos variando de 22,4 a $34,7 \mathrm{~g}$, rendimento de arilo de 37,5 a 41,4\% e 17,8 a 20,4 ${ }^{\circ}$ Brix para sólidos solúveis.

Desse modo, há necessidade de avaliação das características físico-químicas dos frutos para selecionar genótipos mais uniformes em produção e qualidade e adaptáveis às condições climáticas da região produtora. Portanto, para que o cultivo comercial seja viável, é importante que genótipos selecionados reúnam características superiores às plantas em estado natural, principalmente com relação à produtividade, estabilidade na produção e qualidade de frutos (JAGADEESH et al., 2007; GANGA et al., 2010). Assim, uma das estratégias comumente empregadas no melhoramento de fruteiras é a identificação de genótipos superiores em populações naturais segregantes, que possam vir a ser propagadas vegetativamente. Análise de diversidade fenotípica em frutíferas, baseada em características físicas e químicas de frutos, vem sendo utilizada para o desenvolvimento de estratégias de seleção e conservação (SIDINA et al., 2009; UZUN et al., 2009; GANGA et al., 2010). As estimativas de distâncias genéticas baseadas em características morfológicas e quantitativas são estimativas clássicas de diversidade genética utilizadas em muitas espécies vegetais.

Este estudo teve como objetivo avaliar as características físico-químicas dos frutos de rambuteiras em um plantio comercial de árvores pésfrancos em Ituberá-BA, visando a selecionar genótipos com uniformidade nessas características e potenciais matrizes a serem propagadas vegetativamente para cultivo ou utilizadas em programa de melhoramento genético.

\section{MATERIAL E MÉTODOS}

As avaliações foram efetuadas no período de abril a julho de 2005, em três pomares de rambuteiras, localizados no município de Ituberá, Bahia, Brasil (Latitude $13^{\circ} 44^{\prime} \mathrm{S}$ e Longitude $39^{\circ} 9^{\prime} \mathrm{W}$ ). Os pomares totalizavam mais de 1.000 rambuteiras propagadas por sementes, em espaçamentos variando entre $7 \mathrm{x}$ 3 e $8 \times 8 \mathrm{~m}$, e na época da avaliação tinham mais de oito anos de idade. Após a avaliação geral do pomar, foram selecionados 105 genótipos que apresentavam boa produção e frutos com boas características visuais com relação ao tamanho, aparência e coloração entre vermelho-claro e vermelho-escuro. Inicialmente, em cada planta, foram coletados três frutos ao acaso para medição do teor de sólidos solúveis, utilizando-se de um refratômetro portátil. 
Nessa ocasião, avaliou-se também a suculência dos frutos através da degustação da polpa, classificandoos em três tipos: suculentos, suculência média e pouca suculência. Das plantas avaliadas em campo, cujos frutos apresentaram teor de sólidos solúveis em torno de $16^{\circ}$ Brix, foram colhidas amostras de 20 frutos que foram transportados para o Laboratório de Fisiologia Vegetal do Centro de Pesquisa do Cacau (CEPEC), onde foram formadas 3 amostras de 5 frutos cada. A seguir, as amostras foram pesadas para a determinação do peso médio de frutos e das sementes, e calculado o rendimento de arilo pela diferença entre o peso dos frutos e a soma dos pesos das cascas e das sementes. O teor de sólidos solúveis de cada amostra foi medido com um refratômetro digital, a acidez total (\% de ácido cítrico) e o $\mathrm{pH}$, com a utilização de um peagâmetro, de acordo com as normas do Instituto Adolfo Lutz (2005). Os dados dos parâmetros avaliados, referentes aos genótipos, cujos frutos apresentaram peso médio acima de $30 \mathrm{~g}$ e teor de sólidos solúveis igual ou superior a $16^{\circ} \mathrm{Brix}$, conforme preconizado por Kader (2012), foram submetidos à análise de variância, utilizando-se do teste Skott Knott.

Neste trabalho, também foi determinada a matriz de distância euclidiana média padronizada pelo desvio-padrão entre as 20 rambuteiras selecionadas, utilizando-se das características quantitativas e qualitativas de frutos. A matriz foi utilizada como medida de dissimilaridade para a análise de agrupamento, pelo método hierárquico do vizinho mais distante, e a distorção entre as distâncias e o agrupamento, avaliada pelo valor cofenético (CRUZ et al 2011). O ponto de corte para definir os grupos no dendrograma foi obtido pelo Método de Mojena (1977). As análises foram realizadas com o auxílio do aplicativo operacional GENES (CRUZ, 2008).

\section{RESULTADOS E DISCUSSÃO}

Em avaliação visual preliminar, efetuada nos três pomares de rambotã de Ituberá-BA, que precedeu a seleção dos 20 genótipos utilizados neste estudo, foi observada grande variabilidade de frutos relacionada à coloração da casca, tamanho e formato. Com relação à coloração, dos 105 genótipos avaliados, verificou-se que $59 \%$ apresentavam a casca com a cor vermelha, $21 \%$ vermelho-amarela; $16 \%$ cor vermelho-escura e $4 \%$ vermelho-clara (Figura 1A). Comercialmente, rambotãs de coloração variando entre o vermelho-claro e vermelhoescuro apresentam melhor aceitação por parte dos consumidores e melhor aparência na pós-colheita, sendo os frutos de coloração vermelha e vermelhoescura os mais preferidos comercialmente.

A avaliação do teor de sólidos solúveis, efetuada no campo, permitiu verificar uma variação de 9,7 a $21,3{ }^{\circ}$ Brix, sendo que $56,2 \%$ dos genótipos apresentaram frutos com índices acima de $18^{\circ} \mathrm{Brix}$, $20,0 \%$ entre 16 e $18{ }^{\circ}$ Brix e $23,8 \%$ abaixo de $16^{\circ}$ (Figura $1 \mathrm{~B}$ ), sendo este o índice mínimo sugerido por Kader (2012), para seleção de plantas-matrizes.

Referente à suculência do arilo, $67 \%$ dos genótipos avaliados produziram frutos caracterizados como suculentos, $28 \%$ de suculência média e $5 \%$ com pouca suculência (Figura 1C).

Esta avaliação preliminar efetuada em 105 genótipos evidencia a variabilidade existente em pomares de rambotã implantados com mudas propagadas sexuadamente. Andrade et al. (2008) também verificaram grande variabilidade em frutos provenientes de rambuteiras pés-francos avaliados em Jaboticabal.

Na Tabela 1, são apresentados os resultados referentes às características físicas e químicas de frutos de 20 genótipos de rambuteiras que atingiram os índices preconizados como critérios de seleção (frutos acima de $30 \mathrm{~g}$ e teor de sólidos solúvel próximo ou acima de $16{ }^{\circ} \mathrm{Brix}$ ). Com relação ao peso do fruto, verificou-se uma variação de $30,2 \mathrm{~g}$ (G12) a 39,4 (G20). A maior média de peso de fruto encontrado neste trabalho foi detectada no genótipo $\mathrm{G} 20$, estatisticamente igual às médias de outros quatro genótipos que apresentaram frutos com peso maior que 35 g (G1, G7, G8 e G16). Kader (2012) sugere peso de fruto acima de $30 \mathrm{~g}$. Andrade et al. (2008) encontraram variação de 19,5 a 40,6 g em rambotãs produzidos em Jaboticabal-SP, mas somente 8 dos 18 genótipos avaliados produziram frutos com peso superior a $30 \mathrm{~g}$, e Arenas et al. (2010) encontraram apenas 2 das 5 plantas, avaliadas no México, com essa característica. O peso do fruto pode ser influenciado por fatores bióticos e abióticos, mas no caso do rambotã que é produzido em cachos tipo racemo, esse atributo pode ser influenciado, também, pelo número de frutos fixados em cada cacho, uma vez que não é feito raleamento de frutos.

Nas sementes, observa-se grande variação em peso $(1,79$ a 3,44 g), valores um pouco superiores aos relatados por Andrade et al. (2008), os quais relatam 1,65 a $2,30 \mathrm{~g}$.

Uma das características desejáveis nos frutos é o rendimento de arilo, parte comestível do rambotã. Nos genótipos avaliados neste trabalho, o rendimento de arilo variou de $35,1 \%$ (G3 e G14) a 50,2\% (G13) e pelo menos 14 dos 20 genótipos produziram frutos com rendimento de arilo acima de $40 \%$. Conforme 
Arenas et al. (2010), nos países produtores de rambotã, têm sido adotados rendimentos de arilo acima de $35 \%$, entretanto Pohlan et al. (2010) recomendam índices de rendimento de arilo acima de $45 \%$.

Com relação ao teor de sólidos solúveis, os genótipos apresentam média de $17,6^{\circ} \mathrm{Brix}$, e à exceção de G1 $\left(15,8^{\circ} \mathrm{Brix}\right)$, os demais apresentaram valores acima de $16,0^{\circ}$ Brix, atendendo assim ao índice de seleção sugerido por Kader (2012). Observa-se que os genótipos G4, G5, G6, G8, G9, G10, G13, G16 e G19 apresentaram teores de sólidos solúveis iguais ou superiores a $18{ }^{\circ} \mathrm{Brix}$, atendendo também às recomendações sugeridas por Medlicott (2012) e Pohlan et al. (2010). Em frutos produzidos em Ituberá-BA, Sacramento et al. (2007) encontraram teores de sólidos solúveis variando de 10,8 a $19,7^{\circ}$ Brix, e apenas 8 em 18 genótipos produziram frutos com sólidos solúveis acima 16 ${ }^{\circ}$ Brix e apenas 2 genótipos com frutos acima de $18{ }^{\circ}$ Brix. Em Jaboticabal-SP, Andrade et al. (2008) verificaram variação no teor de sólidos solúveis de 7,93 a 19,50 ${ }^{\circ}$ Brix, e 11 dos 18 genótipos de rambotã avaliados apresentaram sólidos solúveis acima de 16 ${ }^{\circ}$ Brix, e apenas 4 genótipos com frutos com sólidos solúveis acima de $18^{\circ}$ Brix.

Os teores de sólidos solúveis dos frutos podem ser influenciados por diversos fatores bióticos e abióticos, e tanto a alta temperatura como o excesso de chuvas podem contribuir para a redução do açúcar nos frutos. Na região de Ituberá, a temperatura média é de $25^{\circ} \mathrm{C}$, com mínimas sempre acima de $19{ }^{\circ} \mathrm{C}$ e precipitação de $1.800 \mathrm{~mm}$ bem distribuída durante o ano, o que contribui para o constante crescimento vegetativo da rambuteira em detrimento ao direcionamento de fotossintetizados para os frutos. Apesar desses fatores, observou-se um número satisfatório de genótipos cujos frutos apresentam teores de sólidos solúveis acima de $16^{\circ} \mathrm{Brix}$, índice minimo recomendado por Kader (2012).

A acidez titulável variou de 0,19 a $0,86 \%$, com valores extremos menores que os observados por Sacramento et al. (2007) (0,58 a 1,21\%) em ItuberáBA, e por Andrade et al. (2008) (0,33 a 2,04\%) em Jaboticabal-SP. Arenas et al. (2010) relatam valores de acidez variando de 0,20 a $0,28 \%$ em frutos produzidos no México. Conforme Kader (2012), é desejável um índice em torno de $0,36 \%$ para o rambotã, entretanto Pohlan et al. (2007) citam teores de acidez titulável de 0,23 e $0,15 \%$, respectivamente, para frutos maduros das variedades R3 e R156.

Observa-se que os genótipos G1, G2, G4, G5, G12, G14 e G16 apresentaram valores de acidez abaixo de 0,30\%, e G3, G6, G7, G8, G9, G11, G13,
G17, G19 e G20, acima de 0,40\%. Em avaliações degustativas efetuadas em campo, foi observado que alguns frutos, apesar do alto teor de sólidos solúveis, apresentavam sabores relativamente insípidos, por causa da baixa acidez. De acordo com Chitarra e Chitarra (2008), o balanço entre sólidos solúveis e acidez (ratio) é importante para conferir sabor ao fruto, e é uma das melhores formas de avaliação do sabor, sendo mais representativo que a medição isolada do açúcar ou da acidez. Essa relação é utilizada para frutos cítricos, abacaxi e uvas, entre outros, mas no caso do rambotã não há citação sobre essa relação. No presente trabalho, a relação sólidos solúveis/acidez variou de 20,6 (G7) a 95,7 (G16), caracterizando uma ampla faixa de sabores.

Considerando todas as características físicas e químicas dos frutos e o atendimento aos padrões adotados em outros países produtores (peso acima de $30 \mathrm{~g}$, rendimento de arilo acima de $35 \%$ e sólidos solúveis acima de $16 \%$ ), poderiam ser eleitos 19 genótipos, como promissores, sem levar em conta a acidez. Portanto, observa-se que, numa amostra de 105 plantas avaliadas em campo, apenas 19,05\% reuniram os critérios de peso e teor de sólidos solúveis sugeridos como padrão de qualidade de rambotãs.

O agrupamento dos 20 genótipos com base nas distâncias genéticas encontra-se na Figura 2. Observa-se a formação de quatro grupos, tomando por base o ponto de corte 25,7 (64\%) no dendrograma.A correlação cofenética foi de 0.60 , mostrando boa correlação entre o agrupamento e as distâncias originais. Quanto aos quatro grupos formados, sendo que em um deles o encontra um único genótipo G20; no outro, dois genótipos G5 e G16; no terceiro, cinco genótipos G7, G8, G13, G19 e G3; e no quarto, os demais genótipos. Os genótipos contidos dentro de cada um desses grupos guardam entre si maiores similaridades quanto às características avaliadas, o que facilita o trabalho de seleção de indivíduos superiores, especialmente se o objetivo for a multiplicação vegetativa de plantas com características mais uniformes Os genótipos G11 e G17 possuem a menor distância $(1,1)$, e os genótipos G5 e G20 a maior distância $(40,2)$; portanto, esses pares de indivíduos são os mais e menos similares, respectivamente. Esses dados mostram ainda que os genótipos em estudo possuem diversidade genética que pode ser aproveitada em trabalho de melhoramento. Os indivíduos com características superiores em cada um dos grupos podem ser selecionados para cruzamento artificial, visando à obtenção de uma população segregante para seleção de genótipos superiores. 
TABELA 1 - Características físicas e químicas de frutos de genótipos de rambuteira cultivados em ItuberáBA, 2005.

\begin{tabular}{ccccccccc}
\hline Genótipos & $\begin{array}{c}\text { Fruto } \\
(\mathrm{g})\end{array}$ & $\begin{array}{c}\text { Semente } \\
(\mathrm{g})\end{array}$ & $\begin{array}{c}\text { Arilo } \\
(\%)\end{array}$ & $\begin{array}{c}\text { Sólidos } \\
\text { Solúveis } \\
\left({ }^{\circ} \text { Brix }\right)\end{array}$ & $\begin{array}{c}\text { Acidez } \\
\text { Titulável } \\
(\%)\end{array}$ & $\mathrm{pH}$ & $\begin{array}{c}\text { Relação } \\
\text { S.solúveis } \\
\text { Acidez }\end{array}$ \\
\hline 1 & $36,4 \mathrm{a}$ & $2,02 \mathrm{~d}$ & $46,2 \mathrm{a}$ & $15,8 \mathrm{c}$ & $0,26 \mathrm{e}$ & $3,49 \mathrm{~d}$ & $60,1 \mathrm{~b}$ \\
2 & $30,8 \mathrm{~b}$ & $2,85 \mathrm{~b}$ & $47,8 \mathrm{a}$ & $16,8 \mathrm{c}$ & $0,19 \mathrm{e}$ & $4,24 \mathrm{a}$ & $83,8 \mathrm{a}$ \\
3 & $32,3 \mathrm{~b}$ & $3,44 \mathrm{a}$ & $35,1 \mathrm{c}$ & $17,8 \mathrm{~b}$ & $0,52 \mathrm{c}$ & $3,51 \mathrm{~d}$ & $34,6 \mathrm{c}$ \\
4 & $31,3 \mathrm{~b}$ & $2,73 \mathrm{~b}$ & $37,8 \mathrm{~b}$ & $18,0 \mathrm{~b}$ & $0,29 \mathrm{e}$ & $4,18 \mathrm{~b}$ & $62,4 \mathrm{~b}$ \\
5 & $32,0 \mathrm{~b}$ & $2,74 \mathrm{~b}$ & $48,5 \mathrm{a}$ & $19,7 \mathrm{a}$ & $0,22 \mathrm{e}$ & $4,36 \mathrm{a}$ & $87,4 \mathrm{a}$ \\
6 & $31,7 \mathrm{~b}$ & $2,01 \mathrm{~d}$ & $40,9 \mathrm{~b}$ & $18,0 \mathrm{~b}$ & $0,49 \mathrm{c}$ & $3,63 \mathrm{c}$ & $36,3 \mathrm{c}$ \\
7 & $37,0 \mathrm{a}$ & $2,66 \mathrm{~b}$ & $41,1 \mathrm{~b}$ & $16,7 \mathrm{c}$ & $0,82 \mathrm{a}$ & $3,49 \mathrm{~d}$ & $20,6 \mathrm{~d}$ \\
8 & $35,2 \mathrm{a}$ & $2,57 \mathrm{~b}$ & $39,7 \mathrm{~b}$ & $18,1 \mathrm{~b}$ & $0,67 \mathrm{~b}$ & $3,42 \mathrm{~d}$ & $26,9 \mathrm{~d}$ \\
9 & $30,5 \mathrm{~b}$ & $2,07 \mathrm{c}$ & $41,7 \mathrm{~b}$ & $18,6 \mathrm{a}$ & $0,59 \mathrm{c}$ & $3,87 \mathrm{~b}$ & $31,6 \mathrm{c}$ \\
10 & $32,6 \mathrm{~b}$ & $2,33 \mathrm{c}$ & $43,1 \mathrm{a}$ & $19,3 \mathrm{a}$ & $0,35 \mathrm{~d}$ & $3,95 \mathrm{~b}$ & $54,5 \mathrm{~b}$ \\
11 & $32,2 \mathrm{~b}$ & $2,47 \mathrm{~b}$ & $42,0 \mathrm{a}$ & $16,4 \mathrm{c}$ & $0,41 \mathrm{~d}$ & $3,82 \mathrm{c}$ & $39,8 \mathrm{c}$ \\
12 & $30,2 \mathrm{~b}$ & $1,97 \mathrm{~d}$ & $45,4 \mathrm{a}$ & $17,1 \mathrm{c}$ & $0,19 \mathrm{e}$ & $4,42 \mathrm{a}$ & $95,3 \mathrm{a}$ \\
13 & $33,7 \mathrm{~b}$ & $2,97 \mathrm{~b}$ & $50,2 \mathrm{a}$ & $18,4 \mathrm{~b}$ & $0,86 \mathrm{a}$ & $3,22 \mathrm{~d}$ & $21,6 \mathrm{~d}$ \\
14 & $31,2 \mathrm{~b}$ & $1,79 \mathrm{~d}$ & $35,1 \mathrm{c}$ & $17,9 \mathrm{~b}$ & $0,29 \mathrm{e}$ & $4,28 \mathrm{a}$ & $63,0 \mathrm{~b}$ \\
15 & $32,3 \mathrm{~b}$ & $1,86 \mathrm{~d}$ & $44,5 \mathrm{a}$ & $17,3 \mathrm{c}$ & $0,33 \mathrm{~d}$ & $4,15 \mathrm{~b}$ & $53,3 \mathrm{~b}$ \\
16 & $36,0 \mathrm{a}$ & $3,17 \mathrm{a}$ & $44,2 \mathrm{a}$ & $18,8 \mathrm{a}$ & $0,20 \mathrm{e}$ & $4,00 \mathrm{~b}$ & $95,7 \mathrm{a}$ \\
17 & $33,7 \mathrm{~b}$ & $2,35 \mathrm{c}$ & $39,0 \mathrm{~b}$ & $16,9 \mathrm{c}$ & $0,42 \mathrm{~d}$ & $3,76 \mathrm{c}$ & $39,9 \mathrm{c}$ \\
18 & $31,0 \mathrm{~b}$ & $2,62 \mathrm{~b}$ & $46,0 \mathrm{a}$ & $17,8 \mathrm{~b}$ & $0,34 \mathrm{~d}$ & $4,23 \mathrm{a}$ & $52,9 \mathrm{~b}$ \\
19 & $33,8 \mathrm{~b}$ & $1,96 \mathrm{~d}$ & $43,7 \mathrm{a}$ & $19,1 \mathrm{a}$ & $0,69 \mathrm{~b}$ & $3,38 \mathrm{~d}$ & $27,4 \mathrm{~d}$ \\
20 & $39,4 \mathrm{a}$ & $1,97 \mathrm{~d}$ & $35,6 \mathrm{c}$ & $16,5 \mathrm{c}$ & $0,67 \mathrm{~b}$ & $4,42 \mathrm{a}$ & $25,3 \mathrm{~d}$ \\
\hline Média & 33,2 & 2,40 & 42,3 & 17,6 & 0,44 & 3,92 & 50,1 \\
$\mathrm{~F}$ & $3,76^{* *}$ & $11,85^{* *}$ & $5,88^{* *}$ & $5,32^{* *}$ & $42,57 *$ & $27,88 * *$ & $46,24 * *$ \\
CV \% & 6,70 & 9,43 & 7,80 & 4,40 & 12,7 & 3,10 & 2,02 \\
\hline
\end{tabular}

Médias seguidas por letras distintas, na mesma coluna, diferem entre si, ao nível de 1\%,pelo teste Skot Knott.; ** Significativo a 1\% de probabilidade.

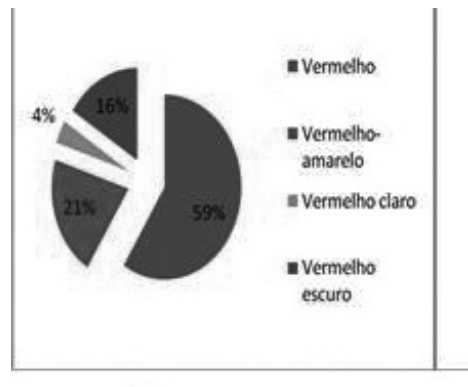

A

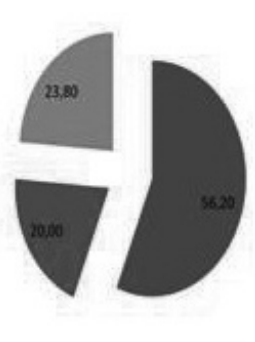

B

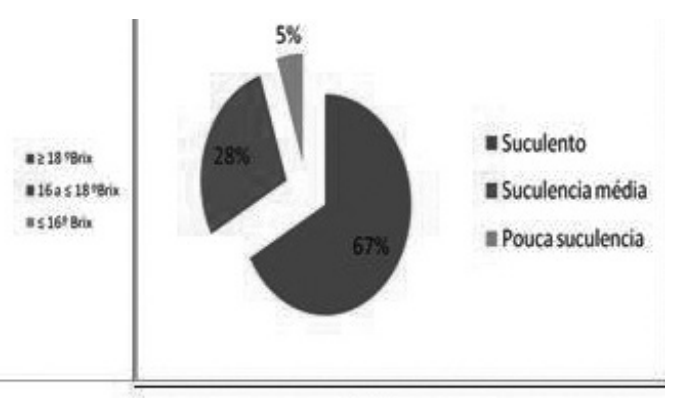

$\mathrm{C}$

FIGURA 1 - Percentuais de genótipos de rambotã de uma amostra de 105 plantas avaliadas com relação ao fruto (A): coloração da casca (B): teor de sólidos solúveis $\left({ }^{\circ} B r i x\right)$ e $(C)$ suculência dos frutos . Ituberá-BA, 2005. 


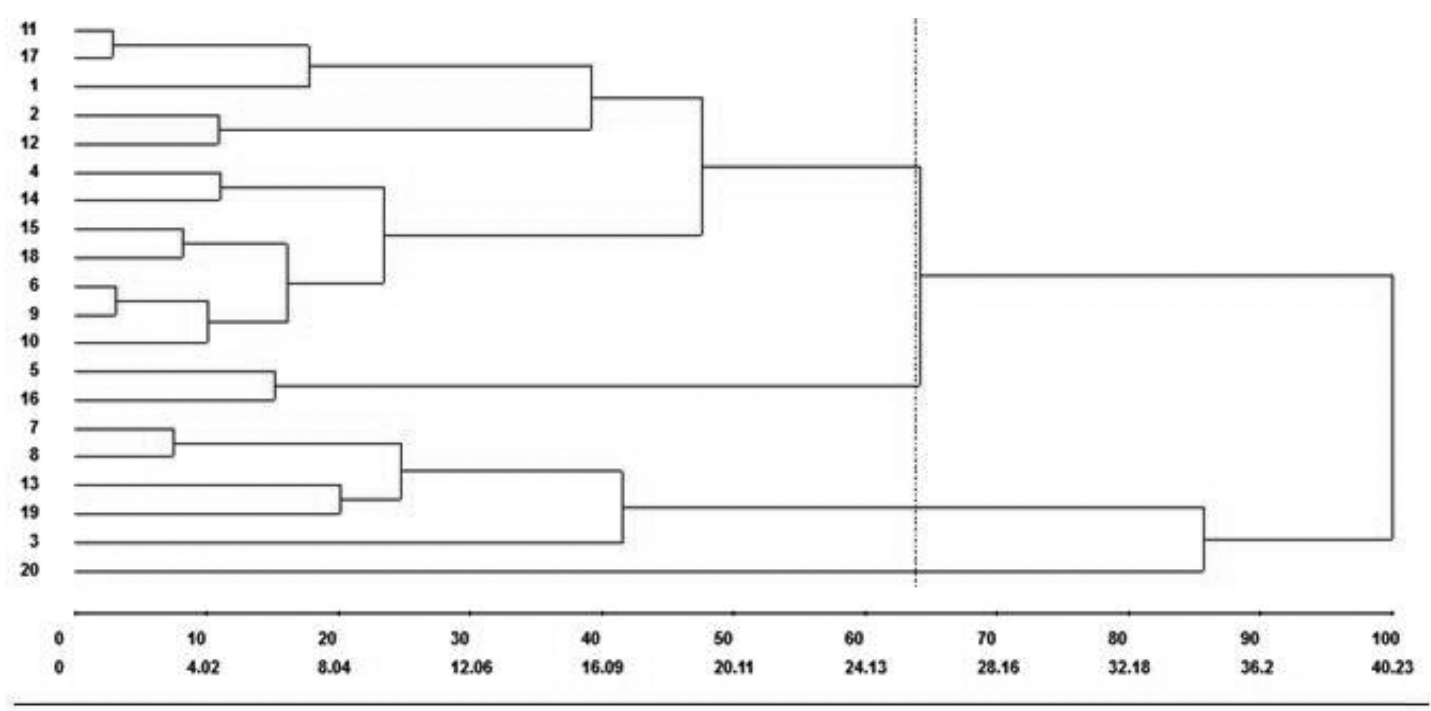

FIGURA 2- Dendrograma baseado na distância euclidiana média ponderada pelo desvio- padrão e método de agrupamento do vizinho mais distante, utilizando sete características físicas e químicas de frutos, em 20 genótipos de rambuteira.

\section{CONCLUSÕES}

Os genótipos avaliados em ItuberáBA, mostram elevada variabilidade fenotípica, o que permite identificar 20 genótipos cujos frutos apresentam características desejáveis para comercialização (peso de fruto acima de $30 \mathrm{~g}$ e teor de sólidos solúveis acima de $\left.16^{\circ} \mathrm{Brix}\right)$.

\section{AGRADECIMENTOS}

Os autores agradecem à FAPESB, pelo apoio financeiro a este projeto, e aos produtores de Ituberá, Takehiro Miyamoto e Akihico Myakawa, pela cessão dos pomares de rambotã para realização das pesquisas, e ao Setor de Fisiologia Vegetal do Centro de Pesquisas do Cacau (CEPLAC), pelo apoio nas análises físico-químicas.

\section{REFERÊNCIAS}

ANDRADE, R.A.; LEMOS, E.G.M.; MARTINS, A.B.G.; PAULA, R.C.; PITTA JÚNIOR, J.L. Caracterização morfológica e química de frutos de rambutan. Revista Brasileira de Fruticultura, Jaboticabal, v. 34, n. 4, p. 958-963, 2008.

ARENAS, M.G.H., ANGEL, D.N., DAMIAN, M.T.M., ORTIZ, D.T., DIAZ, C.N., FONSECA, A.A.O., CONCEIÇÃO M.N. Characterization of rambutan (Nephelium lappaceum) fruits from outstanding mexican selections. Revista Brasileira de Fruticultura, Jaboticabal, v. 32, n. 4, p. 10981104, 2010.

CHITARRA, M.I.F.; CHITARRA, A.B. Pós-colheita de frutas e hortaliças: fisiologia e manuseio. Lavras, UFLA, 2008, $785 \mathrm{p}$.

CRUZ, C. D. Programa genes: diversidade genética. Viçosa: Editora UFV, 2008. v. 1, 278 p.

CRUZ, C. D.; FERREIRA, F.M.; PESSONI, L.A. Biometria aplicada ao estudo da diversidade genética. Viçosa, MG: Editora UFV, 2011.v 1, 620p.

GANGA, R. M. D.; FERREIRA, G. A.; CHAVES, L. J.; NAVES, R. V.; NASCIMENTO, J. L. Caracterização de frutos e árvores de populações naturais de Hancornia speciosa Gomes do cerrado. Revista Brasileira de Fruticultura, Jaboticabal, v. 32, n. 1, p. 101-113, 2010.

INSTITUTO ADOLFO LUTZ. Métodos físicoquímicos para análise de alimentos. 4. ed. Brasília: Ministério da Saúde, 2005. 1018 p.

JAGADEESH, S. L.; REDDY, B. S.; BASAVARAJ, N.; SWAMY, G. S. K.; GORBAL,K.; HEGDE, L.; RAGJAVAN, G. S. V.; KAJJIDONI, S. T. Inter tree variability for fruit quality in jackfruit selections of Western Ghats of India. Scientia Horticulturae, Amsterdam, v. 112, p. 382-387, 2007. 
KADER, A.A. Rambutan: recommendations for maintaining postharvest quality. Disponivel em: $<$ http:postharvest.ucdvis.edu/Produce/ProduceFacts/ Fruit/rambutan.html>. Acesso em: 01 jul. 2010.

MEDLICOTT, A. Harvesting and postharvest handling of rambutan. Disponível em: <http:/// www.fintrac.com/gain/guides/ph/postram.html. Acesso em: 01 jul. 2010.

MOJENA, R. Hierarquical grouping methods and stopping rules; an evauation. Computer Journal, London, v. 20 n. 359-363, 1977.

POHLAN, J.; VANDERLINDEN, E.J.M.; JANSSENS, M.J.J. Harvest maturity, harvesting and field handling of rambutan. Stewart Postharvest Review, v.2, p.11.2008. Disponível em: $<$ http:www. stewartpostharvest.com>. Acesso em: 02 abr. 2010.

SACRAMENTO, C. K. BARRETTO, W. S.; CERQUEIRA, L. S.; BARBOSA, A. M. M.; FARIA, J. C. Análise da qualidade de frutos de genótipos de ramboteiras (Nephelium lappaceum L.) cultivadas na região sul da Bahia. Magistra, Cruz das Almas, v. 19, p. 1-6, 2007.
SACRAMENTO, C. K.; LUNA, J.V.U.; MULLER, C.H.; CARVALHO, J. E. U. NASCIMENTO, W.M.O. Rambotã. In: SANTOS-SEREJO, J.A. et al. (Org.). Fruticultura tropical: espécies nativas e exóticas. Brasília: EMBRAPA, 2009. p. 403-421

SIDINA, M. M.; HANSALI, M. E.; WAHID, N.; OUATMANE, A.; BOULLI, A.; HADDIOUI, A. Fruit and seed diversity of domesticated carob (Ceratonia siliqua L.) in Morocco. Scientia Horticulturae, Amsterdam, v. 123, p. 110-116, 2009.

UZUN, A., GULSEN, O., KAFA, G., SEDAY, U., TUZCU, O., YESILOGLU, T. Characteristics for yield, fruit quality on molecular profiles of lemon genotypes tolerant to 'mal secco' disease. Scientia Horticulturae, Amsterdam, n. 122, p. 556-561, 2009.

WATSON, B.J. Rambutan cultivars in north Queensland. Queensland Agricultural Journal, Brisbane, v.114, n.1, p. 37-41, 1988. 